OPEN ACCESS

Edited by:

Minghui Cai,

Northeastern University, China

Reviewed by:

Jianguo Lin,

Imperial College London,

United Kingdom

Xianhong Han,

Shanghai Jiao Tong University, China

Yu Chen,

Northeastern University, China

${ }^{*}$ Correspondence:

Kai Wang

wangkai@hust.edu.cn

Specialty section:

This article was submitted to

Structural Materials,

a section of the journal

Frontiers in Materials

Received: 14 October 2020 Accepted: 23 November 2020

Published: 11 January 2021

Citation:

Liu Y, Li J, Wang L, Wang K, Zhu B and

Zhang $Y$ (2021) Hot Stamping of a BPillar Reinforced Panel With 7075 Aluminum Alloy and the Feasibility

Study of Short-Time Aging.

Front. Mater. 7:617223.

doi: $10.3389 /$ fmats.2020.617223

\section{Hot Stamping of a B-Pillar Reinforced Panel With 7075 Aluminum Alloy and the Feasibility Study of Short-Time Aging}

\author{
Yong Liu, Jiahao Li, Liang Wang, Kai Wang *, Bin Zhu and Yisheng Zhang \\ State Key Laboratory of Materials Processing \& Die and Mould Technology, School of Materials Science and Engineering, \\ Huazhong University of Science and Technology, Wuhan, China
}

The hot stamping of a B-pillar reinforced panel with 7075 aluminum alloy was carried out in an industrial production line. The effect of blank holding force (BHF) on the formability of the B-pillar reinforced panel and the effect of solution heat treatment (SHT) time on the mechanical properties were studied. Additionally, the forming precisions of a formed part before and after standard aging were detected further. Finally, both standard aging and short-time aging processes were carried out to investigate the feasibility of short-time aging for real parts. The stamping results demonstrated that lower BHF or no blank holding should be used during hot stamping to avoid cracking and wrinkling. The detection of forming precisions indicated that the great majority of measured points on the part were within $\pm 1 \mathrm{~mm}$ of nominal. The mechanical property testing showed that the strength of the formed parts after a short-time aging was up to more than $90 \%$ of the as-received 76 state and more than $93 \%$ of the time can be reduced if the $90 \%$ of strength can be accepted.

Keywords: hot stamping, 7075 aluminum alloy, blank holding force, forming precision, short-time aging

\section{INTRODUCTION}

Increasing attention has been paid to the lightweight qualities of automobiles due to imperious demands for environmental protection and energy-saving. Benefitting from high specific strength, good impact energy absorption, high corrosion resistance and good recyclability, aluminum alloys have been proved to be excellent light material for automobiles (Mohamed et al., 2012; Jürgen, 2014; Ghiotti et al., 2019). When stamped at room temperature, aluminum alloy parts have large springback (Maeno et al., 2017) and sometimes there are cracks in the parts (Liu et al., 2018). Besides, these parts may have thermal deformation during high-temperature heat treatment, e.g. solution heat treatment. Thus, hot stamping for heat-treatable aluminum alloy sheet has been developed (Garrett et al., 2005). During hot stamping of aluminum alloy, the blank is heated up to the SHT temperature and held for a period of time. Then the hot blank is transferred to the cold tools and subsequently formed and quenched in the closed tools, followed by holding in the tools for about $10 \mathrm{~s}$. At last, the aging process is carried out to improve the strength of the formed part.

In short, hot stamping of an aluminum alloy mainly includes three processes: SHT, forming and aging. SHT and aging are heat treatment processes, which means that time and temperature are the main factors affecting the two processes. There is an expected scenario that workpieces with good performance can be obtained on the production line by using appropriate temperature and less time, while maintaining the continuity of the production. For 7075 aluminum alloy, it usually takes more 
than 10 min to complete SHT by conventional means (Liu et al., 2020; Zhang et al., 2020), and the aging treatment needed to obtain maximum aging strength is generally about $120^{\circ} \mathrm{C}$ for $24 \mathrm{~h}$ (Zhang et al., 2020). Not only are the SHT and aging times long, but also the aging time is more than 100 times longer than the SHT time. It means that the production efficiency is low, and the synchronization of production cannot be guaranteed. As a result, it is necessary to develop the innovative methods and processes to reduce the SHT time and aging time. $\mathrm{Xu}$ X et al. (Xu et al., 2015) reduce the aging time by $50 \%$ by adding $\mathrm{Ag}$ into 7075 aluminum alloy. In automotive manufacturing lines, vehicle parts will finally go through a paint bake process $\left(180{ }^{\circ} \mathrm{C} \times 30 \mathrm{~min}\right)$, which can be considered as part of the artificial aging process ( $\mathrm{Li}$ et al., 2015). Combining with the paint bake process, Li N (Li et al., 2015) and Zheng J (Zheng et al., 2019) carried out pre-aging process for 6082, and more than $90 \%$ of the strength at T6 state could be obtained. Omer K et al. (Omer et al., 2018) conducted the aging process for 7075 samples at $120^{\circ} \mathrm{C} \times 3 \mathrm{~h}+177^{\circ} \mathrm{C} \times 0.5 \mathrm{~h}$ and the strength was close to the strength under T6 condition. Sun W et al. (Sun et al., 2019) presented a method of using a controlled, roomtemperature cyclic deformation to sufficiently and continuously inject vacancies into the material and to mediate the dynamic precipitation of a very fine (1- to 2-nm) distribution of solute clusters. This method takes tens of minutes and is currently only suitable for small samples, not for real parts. The results mentioned above were carried out under laboratory conditions, thus, the authors would like to study the feasibility of short-time aging of 7075 aluminum alloy combining with paint bake process on production line, maximizing the post strength of the part and reducing the aging time.

Furthermore, forming is an important procedure in the hot stamping process of aluminum alloy. Parts with no defects and high forming precision are expected to be obtained. Blank holding is often used to avoid or reduce the forming defects like wrinkling. In comparison to cold stamping, the flow stress of the material is relatively low due to the high temperature during hot stamping, while the friction is more serious. Consequently, the parts are prone to crack in the forming process. Considering the friction and low flow stress at high temperature, blank holding may cause fracture during deep drawing. Therefore, it is of significance to study the effect of BHF on the formability of real aluminum alloy parts in hot stamping.

In this paper, hot stamping of a B-pillar reinforced panel with 7075 aluminum alloy was carried out in an industrial production line. The effect of BHF on the formability of the B-pillar reinforced panel and the effect of SHT time on the mechanical properties were studied. Further, the forming precisions of a formed part before and after standard aging were detected. Finally, the standard aging and short-time duplex aging processes were carried out to investigate the feasibility of short-time aging for real parts to reduce the aging time further. It is expected to provide guidance for the forming of aluminum alloy parts with complex geometric shape by hot stamping process in industry.

\section{MATERIALS AND EXPERIMENTS}

A typical commercially available 7075 aluminum alloy was used in this work. The as-received 7075 aluminum alloy was under the T6 condition. Its yield strength (YS) and ultimate tensile strength (UTS) are respectively 532 and $585 \mathrm{MPa}$. The material used does not necessarily represent the microstructure that a production material would have prior to SHT. The dimension of the blank is approximately $1,450 \times 650 \times 1.5 \mathrm{~mm}$ (thickness). Besides, graphite was used as lubricant in the experiment.

The host stamping experiments were carried out in a production line as shown in Figure 1A. A servo press with a tonnage of 1,200 tons and a multilayer chamber furnace were used in the stamping experiments. Figure 1B shows the aging furnace and there is a fan in it to produce more efficient heat convection and make the temperature distribution more uniform. As indicated in literature (Harrison and Luckey, 2014), the SHT for 7075 typically occurs between $460-500{ }^{\circ} \mathrm{C}$. As a result, the SHT temperature was set as $490^{\circ} \mathrm{C}$ in the stamping experiments. All of the formed parts were held in the tools for $10 \mathrm{~s}$ with a pressure of 400 tons after closing the tools. Designed experiment conditions are shown in Table 1. The BHF was controlled by the nitrogen gas spring and the position of the blank holder is shown in Figure 2. The full BHF was 6 tons. The standard aging $\left(\mathrm{SA}, 120^{\circ} \mathrm{C} \times 24 \mathrm{~h}\right)$ process and duplex aging process $\left(\mathrm{DA}, 110^{\circ} \mathrm{C} \times 1 \mathrm{~h}+180^{\circ} \mathrm{C} \times 0.5 \mathrm{~h}\right.$ ) were carried out within $24 \mathrm{~h}$ after quenching. It took about $15 \mathrm{~min}$ for the furnace to reach the heating temperature in the SA process. As for the DA process, it took about $12 \mathrm{~min}$ for the furnace to reach $110^{\circ} \mathrm{C}$ from room temperature and $13 \mathrm{~min}$ to reach $180^{\circ} \mathrm{C}$ from $110{ }^{\circ} \mathrm{C}$. To detect the forming precisions of the part before and after standard aging, the measurements of three-dimensional geometric data were carried out by a blue light scanner.

In order to test the mechanical properties of the formed parts, tension test samples were cut from the formed parts (No. 3-6). The locations and the dimensions of the tension test samples are shown in Figures 3, 4, respectively. It should be noted that because the shape and dimensions of some tension test samples were not suitable for tensile testing, strengths at some locations were not tested. Besides, elongation values at some locations were missing because the fracture locations of these tension samples were out of the gauge range. The drawing speed in tensile tests was $2 \mathrm{~mm} / \mathrm{min}$.

\section{RESULTS AND DISCUSSION}

\section{Effect of Blank Holder Force on the Part's Formability}

The formed parts (No. 1-3) are shown in Figure 5. As can be seen, the formed part with full BHF cracked at both sidewalls of the big end (zones in the red circle in Figure 5A) while the formed part with half BHF only cracked at one sidewall of the big end (zone in the red circle in Figure 5B). Besides, the size of the crack in part with half BHF was smaller than that of the part with full BHF. No cracks were observed in the formed part without BHF. The results indicated that BHF in hot stamping of 7075 aluminum alloys may cause the crack and some researchers also noticed this phenomenon (Zhou et al., 2014). 

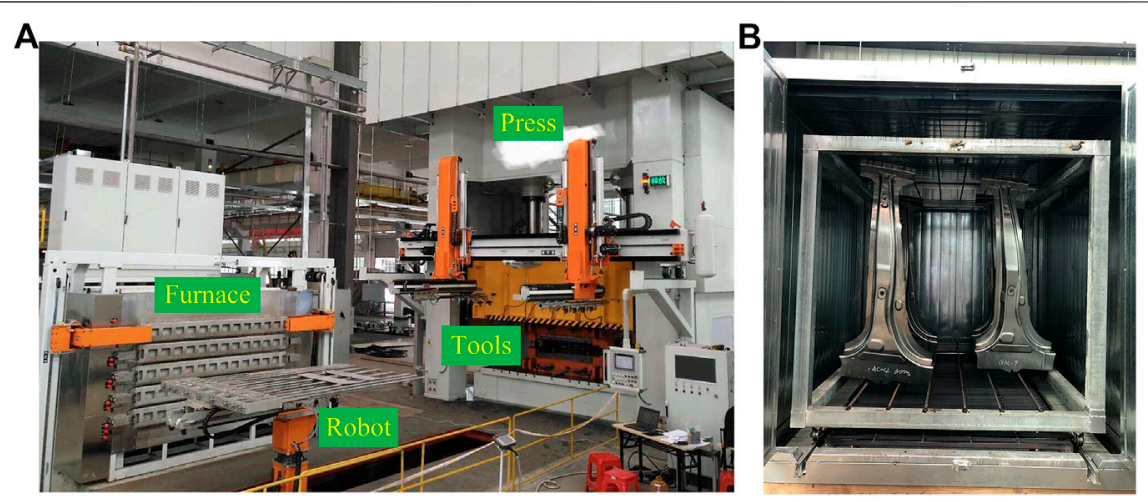

FIGURE 1 | (A) The hot stamping production line and (B) the aging furnace.

TABLE 1 | The designed experiment conditions.

\begin{tabular}{lclc} 
Part Number & SHT time & BHF & Aging process \\
\hline 1 & 15 & Full & SA \\
2 & 15 & Half & SA \\
3 & 15 & None & SA \\
4 & 20 & None & SA \\
5 & 15 & None & DA \\
6 & 10 & None & DA \\
\hline
\end{tabular}

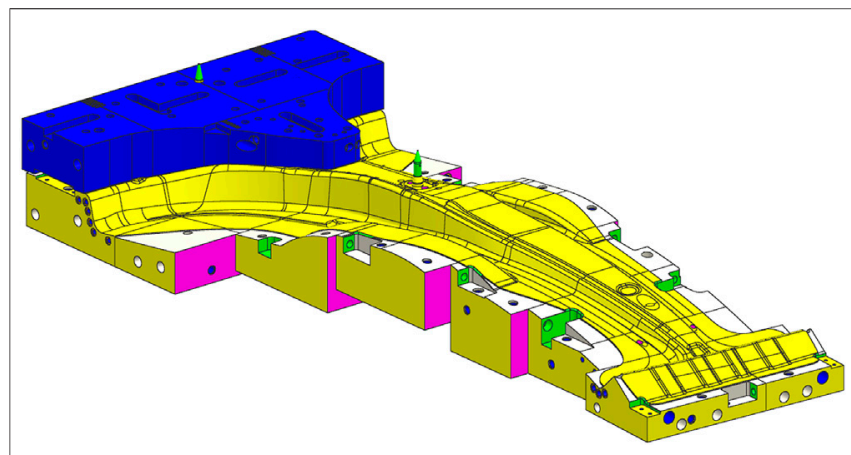

FIGURE 2 | The position of the blank holder.

The cracking mechanism of the formed parts is similar to the cracking mechanism in previous experiments (Liu et al., 2018) and the large friction force caused by BHF in this work replaced the dry friction force in the previous study (Liu et al., 2018). It is well known that the flow stress of 7075 aluminum alloy decreases with the increasing temperature (Ghiotti et al., 2019). As a result, the deformation resistance and the ability to resist tensile stress of 7075 decreased with the increasing temperature. In hot stamping, the hot blank first contacted with the rounded corners of the tools, resulting in the temperature of these regions dropping early and deformation resistance increasing. However, the temperature of the sidewall was relatively higher because of the tool clearance, leading to lower flow stress and weaker ability to resist tensile stress. In the subsequent hot drawing stage, with full BHF, the material in the flange of the big end was held by large friction

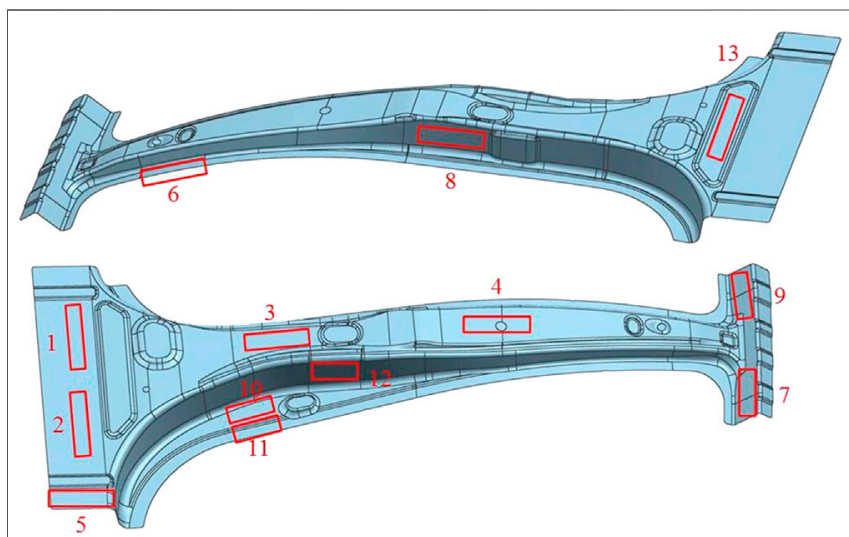

FIGURE 3 | The locations of the tension test samples in the formed parts.

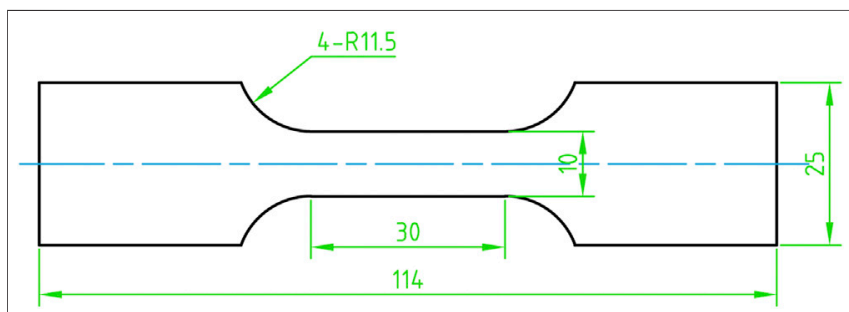

FIGURE 4 | Principle shape and dimensions of the tensile test specimen (unit: $\mathrm{mm}$ ).

force caused by BHF and the material was difficult to draw to the sidewall. As a result, the soft material in the sidewall was eventually stretched to cracking. With lower BHF, the material in the flange was easy to flow to the sidewall with the assistance of lubricants, and thus the size of the crack reduced or even there were no cracks in the formed parts. Nevertheless, during hot stamping, a blank holder should have been designed to avoid wrinkling. Accordingly, a balance must be achieved to avoid 

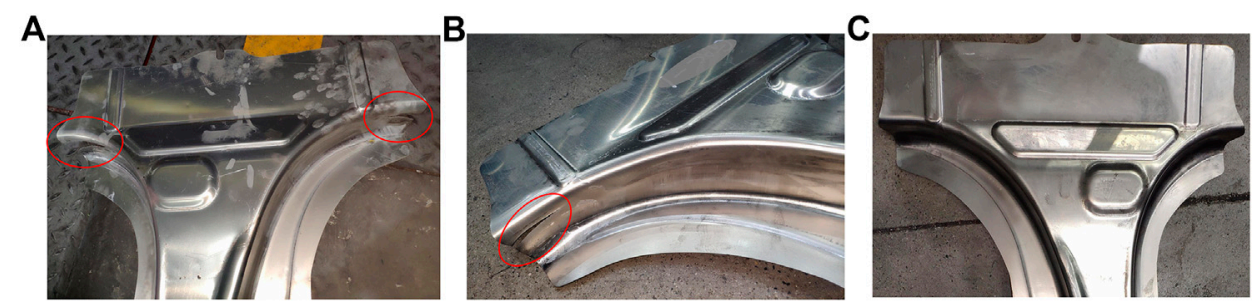

FIGURE 5 | Formed parts: (A) Part No. 1, with full BHF; (B) Part No. 2, with half BHF; (C) Part No. 3, no BHF.
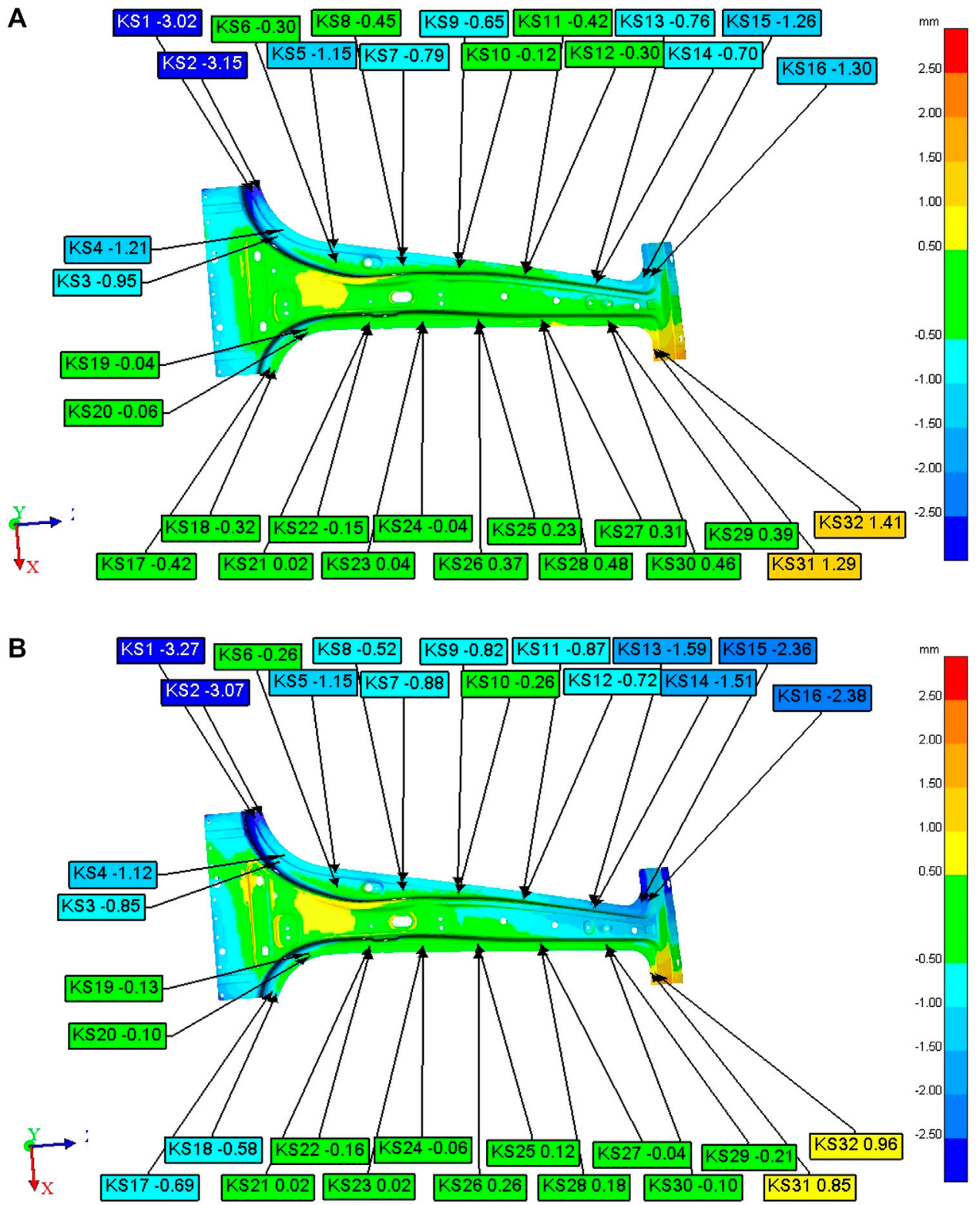

FIGURE 6 | The forming precisions of the part (A) before and (B) after standard aging. 

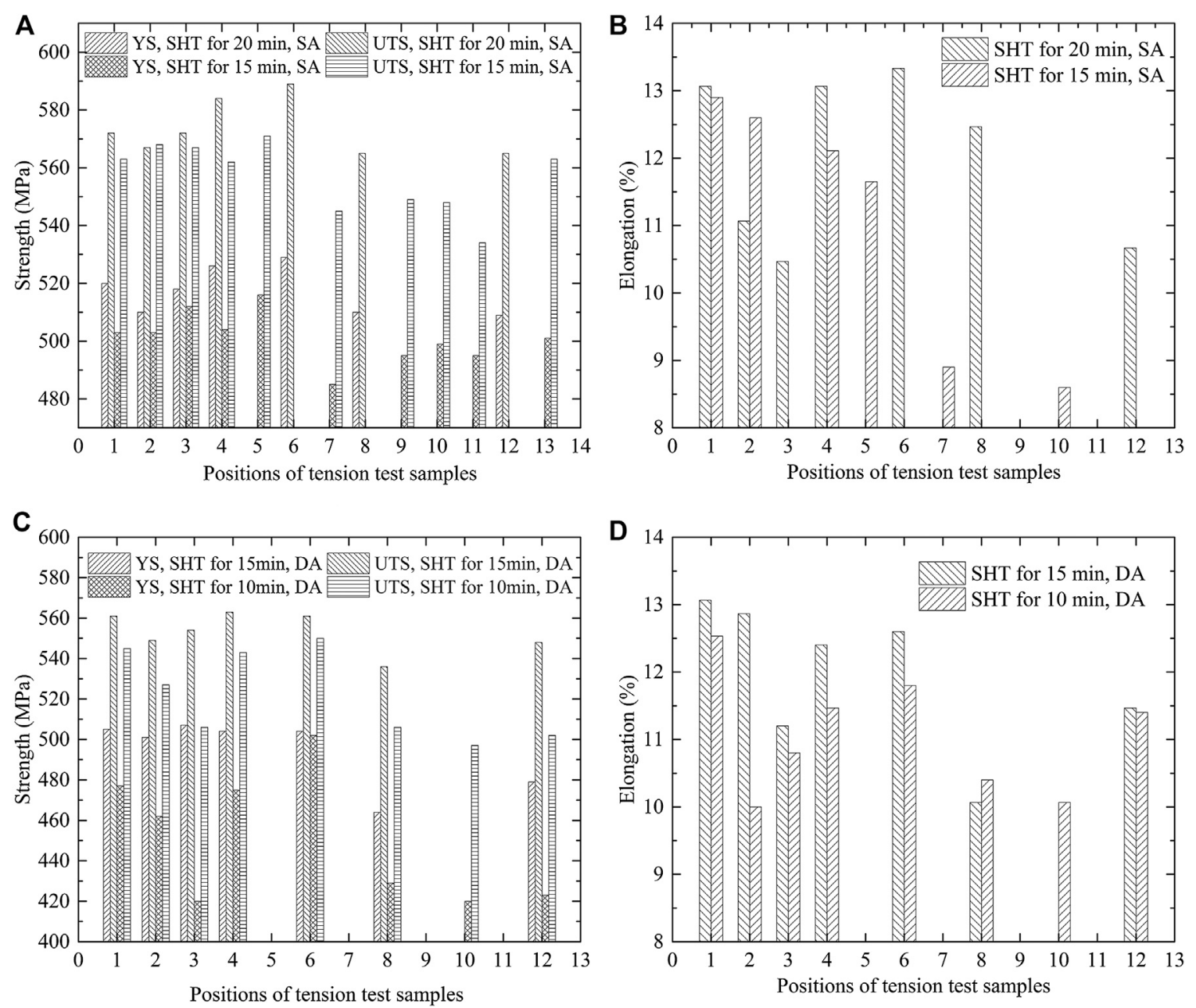

FIGURE 7 | Strength and elongation of samples under different process parameters.

wrinkling and cracking. In respect to the stamping experiments, lower BHF could be conducive to realize the balance between these two conflict factors.

In addition, it is promising to avoid wrinkling and cracking under the conditions of blank holding by reducing the forming temperature. In order to ensure the cooling rate of aluminum alloy sheet during quenching, some cooling methods could be used to make the blank temperature drop quickly to the forming temperature before the part is formed in the tools, which can be called hot stamping with pre-cooling (Zhu et al., 2019). Under this circumstance, the flow stress of the sheet is higher due to the lower temperature, and thus, larger BHF can be used to avoid wrinkling. Furthermore, it might also be useful to avoid wrinkling and cracking if the region of the part that is easily wrinkled can be formed before other regions. These two methods need to be studied in future work.

\section{Forming Precisions of the Part Before and After Standard Aging}

The measured three-dimensional geometric data of the B-pillar reinforced panel were compared with the original CAD model as shown in Figure 3. The forming precisions of the part before and after standard aging are shown in Figure 6. The great majority of measured points on the part are within $\pm 1 \mathrm{~mm}$ of nominal. There is a maximum error of about $3 \mathrm{~mm}$ in the local regions of both ends of the part. It is clear that there are some yellow regions near the big end, indicating that the forming precisions in these regions are insufficient. In fact, this is due to the absence of BHF, which leads to wrinkling. Due to the effect of thermal deformation and residual stress releasing, the forming precisions decrease after aging. However, the reduction of forming precisions is not significant. Although these geometric data respectively represent a small sample size for the formed part, the magnitude of the deviations is acceptable.

\section{Effect of SHT Time on the Mechanical Properties and Short-Time Aging}

The strength and elongation of samples under different process parameters are shown in Figure 7 , and the corresponding statistical results are shown in Table 2 . The strength and 
TABLE 2 | The statistical results of strength and elongation of samples under different process parameters.

\begin{tabular}{|c|c|c|c|c|c|c|c|}
\hline Aging process & SHT time (min) & Category & Mean values & Standard deviation & Minimum values & Maximum values & Minimum/As-received \\
\hline \multirow[t]{6}{*}{ SA } & 20 & YS (MPa) & 517.4 & 8.1 & 509 & 529 & $95.7 \%$ \\
\hline & & UTS (MPa) & 573.4 & 8.1 & 565 & 589 & $96.6 \%$ \\
\hline & & Elongation & 12.0 & 1.2 & 10.5 & 13.3 & - \\
\hline & 15 & YS (MPa) & 501.3 & 8.8 & 485 & 516 & $91.1 \%$ \\
\hline & & UTS (MPa) & 557 & 12.2 & 534 & 571 & $91.3 \%$ \\
\hline & & Elongation & $11.1 \%$ & 1.9 & $8.6 \%$ & $12.9 \%$ & - \\
\hline \multirow[t]{6}{*}{ DA } & 15 & YS (MPa) & 494.9 & 16.6 & 464 & 507 & $87.2 \%$ \\
\hline & & UTS (MPa) & 553.1 & 9.7 & 536 & 563 & $91.6 \%$ \\
\hline & & Elongation & 12.0 & 1.1 & 10.1 & 13.1 & - \\
\hline & 10 & YS (MPa) & 451 & 32.0 & 420 & 502 & $78.9 \%$ \\
\hline & & UTS (MPa) & 522 & 21.8 & 497 & 550 & $85.0 \%$ \\
\hline & & Elongation & 11.1 & 0.9 & 10 & 12.5 & - \\
\hline
\end{tabular}

elongation of samples with a standard aging process under different SHT times are illustrated in Figures 7A,B. As can be seen, formed parts with higher SHT times had larger values of YS and UTS. The elongations of samples subjected to SHT for 20 and $15 \mathrm{~min}$ were in a range of $10.5-13.3 \%$ and $8.6-12.9 \%$, respectively. The values of YS, UTS and elongation were different at different locations in the formed parts because of the testing errors and different cooling rates during quenching due to the contact conditions differences between the blanks and tools. The minimum strength of the part subjected to SHT for 20 min was about $96 \%$ of that of the as-received T 6 condition and the maximum strength was slightly greater than the as-received T6 condition. The variations of strength mainly resulted from the fact that the SHT temperature, cooling rate and aging process may be different from the process parameters used in this work.

Figures 7C,D show the strength and elongation of samples treated by the duplex aging process with different SHT times. Similarly, formed parts subjected to SHT for $15 \mathrm{~min}$ had larger values of YS and UTS than that of parts subjected to SHT for $10 \mathrm{~min}$. The elongations of samples subjected to SHT for 15 and $10 \mathrm{~min}$ under the duplex aging process were in a range of $10.1-13.1 \%$ and $10-12.5 \%$, respectively. The minimum YS of formed parts subjected to SHT for 15 min was only $87.2 \%$ of that of the as-received T6 condition and the minimum UTS was $91.6 \%$ of that of the asreceived T6 condition. In comparison, both of the minimum YS and UTS of formed parts subjected to SHT for 10 min were lower than $90 \%$ of the YS and UTS of the as-received T6 condition.

It has been indicated that the solution is a process which was mainly controlled by diffusion and the diffusion of the alloying elements inside the solvent matrix consumes most of the whole time in SHT (Mohamed et al., 2008). As a result, more alloying elements or precipitates will dissolve into the matrix when the SHT time is longer under the same SHT temperature. Subsequently, more fine precipitates form after quenching and aging. Therefore, the strength is improved when the SHT time is longer.

Aging is a process that includes nucleation and growth of the precipitates, and the growth of the precipitates is solely controlled by diffusion in the matrix (Du et al., 2016). Besides, there exists one or more transition precipitating phases during the aging process of aluminum alloys. As a consequence, dissolution of precipitated phases also takes place during aging. Diffusion coefficient increases with the increasing temperature, resulting in the reduction of diffusion time at elevated temperatures. Therefore, a relatively higher aging temperature can reduce the aging time. However, on the other hand, the required precipitation phases or nucleation cores dissolve if the aging temperature is too high, even the coarse precipitates form and the strength decreases. As a result, the aging temperature should be chosen appropriately. In order to reduce the whole aging time, the multistage aging process may be a good choice. The specific principle is that a relatively high density of GP region forms at a lower temperature to provide a nucleation core for the formation of subsequent transition phases. The transition phase with a suitable shape and strengthening effect can be obtained by using a higher temperature and a shorter time in the subsequent aging process. This method not only makes use of the short-time aging at high temperature, but also avoids the massive dissolution of the nucleation cores.

The short-time aging experiment shows that the obtained strength of the full-scale part can be more than $90 \%$ of that of the as-received T6 condition under the duplex aging process of $110^{\circ} \mathrm{C} \times 1 \mathrm{~h}+180^{\circ} \mathrm{C}$ $\times 0.5 \mathrm{~h}$. Compared to the standard aging process, the new short-time aging process can reduce more than $93 \%$ of the time if $90 \%$ of the T6 strength can be accepted. Besides, increasing the SHT temperature can also increase the part's strength after aging (Li et al., 2015). Therefore, the strength of formed part has a promising outlook to be improved further by increasing the SHT temperature.

\section{CONCLUSION}

(1) Large BHF in hot stamping of 7075 aluminum alloys caused the crack. The material in the flange was hard to flow to the sidewall due to large friction force caused by BHF, and the material in the sidewall was easily stretched under a relatively higher temperature because of non-uniform cooling, thus the parts cracked. Parts with no cracks can be obtained without BHF, but there are wrinkling on the parts. Methods to avoid wrinkling and cracking should be studied in future works.

(2) The great majority of measured points on the part were within $\pm 1 \mathrm{~mm}$ of nominal, and there is a maximum error of about $3 \mathrm{~mm}$ in the local regions of both ends of the part. The forming precisions decrease after aging due to thermal deformation and release of the residual stress. However, the reduction of the forming precisions is small. 
(3) The strength of the part can be improved by increasing the SHT time properly, since more alloying elements or precipitates will dissolve into the matrix when the SHT time is longer.

(4) Under the duplex aging process of $110^{\circ} \mathrm{C} \times 1 \mathrm{~h}+180{ }^{\circ} \mathrm{C} \times$ $0.5 \mathrm{~h}$, the obtained strength of the full-scale part can be more than $90 \%$ of that of the as-received T6 condition. Compared to the standard aging process, the new short-time aging process can reduce more than $93 \%$ of the time if $90 \%$ of the T6 strength can be accepted.

\section{DATA AVAILABILITY STATEMENT}

The raw data supporting the conclusions of this article will be made available by the authors, without undue reservation.

\section{REFERENCES}

Du, Q., Holmedal, B., Friis, J., and Marioara, C. D. (2016). Precipitation of nonspherical particles in aluminum alloys Part II: numerical simulation and experimental characterization during aging treatment of an $\mathrm{Al}-\mathrm{Mg}-\mathrm{Si}$ alloy. Metall. Mater. Trans. A. 47A, 589-599. doi:10.1007/s11661-015-3196-6

Garrett, R. P., Lin, J., and Dean, T. A. (2005). Solution heat treatment and cold die quenching in forming AA6xXX sheet components: feasibility study. Adv. Mater. Res. 6, 673-680. doi:10.4028/www.scientific.net/AMR

Ghiotti, A., Simonetto, E., and Bruschi, S. (2019). Influence of process parameters on friction behaviour of AA7075 in hot stamping. Wear. 426-427, 348-356. doi:10.1016/j.wear.2018.11.031

Harrison, N. R., and Luckey, S. G. (2014). Hot stamping of a B-pillar outer from high strength aluminum sheet AA7075. SAE Int. J. Mater. Manuf. 7, 567-573. doi:10.4271/2014-01-0981

Jürgen, H. (2014). Recent development in aluminium for automotive applications. Trans. Nonferrous Metals Soc. China. 24, 1995-2002. doi:10.1016/S10036326(14)63305-7

Li, N., Zheng, J., Zhang, C., Zheng, K., Lin, J., and Dean, T. A. (2015). Investigation on fast and energy-efficient heat treatments of AA6082 in HFQ processes for automotive applications. MATEC Web Conf. 21, 05015. doi:10.1051/matecconf/ 20152105015

Liu, Y., Zhu, B., Wang, Y., Li, S., and Zhang, Y. (2020). Fast solution heat treatment of high strength aluminum alloy sheets in radiant heating furnace during hot stamping. Int. J. Lightweight Mater. Manuf. 3, 20-25. doi:10.1016/j.jilmm.2019.11.004

Liu, Y., Zhu, Z., Wang, Z., Zhu, B., Wang, Y., and Zhang, Y. (2018). Flow and friction behaviors of 6061 aluminum alloy at elevated temperatures and hot stamping of a B-pillar. Int. J. Adv. Manuf. Technol. 96, 4063-4083. doi:10.1007/ s00170-018-1790-7

Maeno, T., Mori, K., and Yachi, R. (2017). Hot stamping of high-strength aluminium alloy aircraft parts using quick heating. CIRP Ann.-Manuf. Technol. 66, 269-272. doi:10.1016/j.cirp.2017.04.117

Mohamed, M., Alistair, F., and Lin, J. (2008). "Solution heat treatment in HFQ process," in 12th International Conference on Metal Forming. (Dusseldorf, Germany: Verlag Stahleisen GmbH), 160-167.

Mohamed, S. M., Alistair, D. F., Lin, J., Daniel, S. B., and Trevor, A. D. (2012). Investigation of deformation and failure features in hot stamping of AA6082:

\section{AUTHOR CONTRIBUTIONS}

The corresponding author is responsible for ensuring that the descriptions are accurate. YL: writing original draft, implementation of the experiments and data processing. JL: implementation of hot stamping and tensile testing. LW: supply of production line. KW: modifying and editing. BZ: suggestion and resource. YZ: supply of 7075 aluminum alloys and resource.

\section{FUNDING}

This research work was financially supported by the National Major Science and Technology Project of China (Grant No. 2018zx04023001).

experimentation and modelling. Int. J. Adv. Manuf. Technol. 53, 27-38. doi:10. 1016/j.ijmachtools.2011.07.005

Omer, K., Abolhasani, A., Kim, S., Nikdejad, T., Butcher, C., Wells, M., et al. (2018). Process parameters for hot stamping of AA7075 and D-7Xxx to achieve high performance aged products. J. Mater. Process. Technol. 257, 170-179. doi:10. 1016/j.jmatprotec.2018.02.039

Sun, W., Zhu, Y., Marceau, R., Wang, L., Zhang, Q., Gao, X., et al. (2019). Precipitation strengthening of aluminum alloys by room-temperature cyclic plasticity. Sci. 363, 972-975. doi:10.1126/science.aav7086

Xu, X., Zhao, Y., Wang, X., Zhang, Y., and Ning, Y. (2015). The rapid age strengthening induced by Ag additions in 7075 aluminum alloy. Mater. Sci. Eng. A. 648, 367-370. doi:10.1016/j.msea.2015.09.044

Zhang, Z., Yu, J., and He, D. (2020). Effects of contact body temperature and holding time on the microstructure and mechanical properties of 7075 aluminum alloy in contact solid solution treatment. J. Alloys Compd. 823, 153919. doi:10.1016/j.jallcom.2020.153919

Zheng, J., Dong, Y., Zheng, K., Dong, H., Lin, J., Jiang, J., et al. (2019). Experimental investigation of novel fast-ageing treatments for AA6082 in supersaturated solid solution state. J. Alloys Compd. 810, 151934. doi:10.1016/j.jallcom.2019. 151934

Zhou, J., Wang, B., Lin, J., Fu, L., and Ma, W. (2014). Forming defects in aluminum alloy hot stamping of side-door impact beam. Trans. Nonferrous Metals Soc. China. 24, 3611-3620. doi:10.1016/S1003-6326(14)63506-8

Zhu, L., Liu, Z., and Zhang, Z. (2019). Investigation on strengthening of 7075 aluminum alloy sheet in a new hot stamping process with pre-cooling. Int. J. Adv. Manuf. Technol. 103, 4739-4746. doi:10.1007/s00170-019-03890-0

Conflict of Interest: The authors declare that the research was conducted in the absence of any commercial or financial relationships that could be construed as a potential conflict of interest.

Copyright (c) $2021 \mathrm{Liu}, \mathrm{Li}$, Wang, Wang, Zhu and Zhang. This is an open-access article distributed under the terms of the Creative Commons Attribution License (CC $B Y)$. The use, distribution or reproduction in other forums is permitted, provided the original author(s) and the copyright owner(s) are credited and that the original publication in this journal is cited, in accordance with accepted academic practice. No use, distribution or reproduction is permitted which does not comply with these terms. 